\title{
Fashion Choices of Gen Y in Retrospective
}

\author{
Nithyaprakash $\mathrm{V}^{*}$ \\ Department of Fashion Technology, Bannari Amman Institute of Technology, India
}

Received: 制 January 27, 2018; Published: 眥 February 13, 2018

*Corresponding author: Nithyaprakash V, Associate Professor, Department of Fashion Technology, Bannari Amman Institute of Technology, Sathy, Erode, India, Tel: 91-9952497366; Email: nithyaprakash.v@gmail.com

\begin{abstract}
Gen Y's lifestyle is analogous to America's 20th century professional woman trying to live outside the traditional parameters of the society. The movements of Pre-Raphaelites, early 20th century Hollywood stars, Bohemianism in the early stages, Style preferences of BCBG: Bon Chic Bon Genre and current deconstructed silhouettes reveal the traits of free spiritedness, not just because it adds on personal flavour but rather free spiritedness evolution as a way of life and attitude.
\end{abstract}

Keywords: Bohemian; BCBG; Deconstructed; Non-Bourgeois; Gen Y

\section{Introduction}

Two biggest movements of our time ARTISAN and WELLNESS BOOM has well forayed the households of nuclear families and individuals of GEN Y. Ibiza island lifestyle is a classic example of modern euphoria based on wellness and spirituality [1]. The lifestyle of GEN Y has been marked by their self confidence in choosing the way they wish to live in the present often ready to explore \& elicit emotional responses amidst balancing their strengths and weakness [2]. Moreover the intention to live out i.e. away from the parents is increasingly witnessed in all parts of the globe among the youngsters. This is analogous to situation that prevailed in America by the beginning of 20th century when an increasing number of professional women were attempting to live outside the traditional parameters of society. Spurred on by the movements such as rational dress society (1881), Pre-Raphaelites, musical stars and Hollywood stars, bohemianism reflected in a sort of lifestyle itself [3]. The term "bohemian" applies to people who choose to live unconventional, artistic lives meanwhile the original meaning references travellers or refuges from central Europe rather popularly addressed as gypsies [4].

Painter Vasily Kandinsky's non-objective style of art using geometric shapes and colours did occasionally culminate in designing dress for his wife in an unconventional style [5]. Rather in other words, looking forward for the simplest innovative solution to an existing problem, worthy of lifestyle traits and desires has been a code word for Gen Y. This provides an opportunity for the brands to push the boundaries of aesthetics, create new codes mixing references of street wear and luxury [6]. Let us investigate the Interpolations and deconstructions of Bohemianism and Bon chic Bon genre to discover the most likely expectant fashion choices of Gen Y.

\section{Bohemianism in Fashion - The Early Stages}

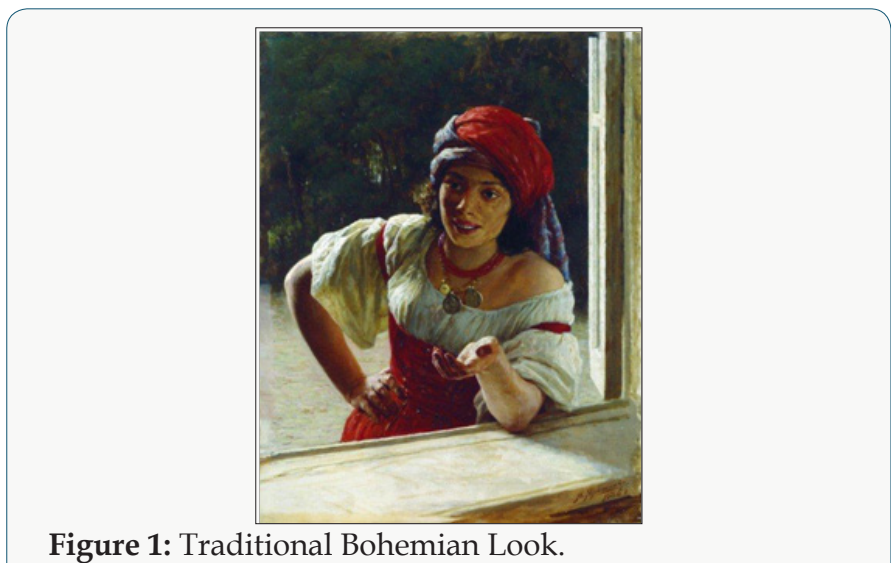

Alongside Romantic Movement, for the first time, bohemian dress ended up as representative and expressive of an individual personality highlighting their poverty and originality [7]. The fashion style of "boho-chic" that prevailed in the early years of the 21 st century is in contrast to the late 19th century and first half of the 20th, where the Bohemian fashion reflected the lifestyle 
itself [8] (Figure 1). In the early 20th century, full skirts and bright colours of the Dorothy "Dorelia" McNeill (1881-1969), muse and second wife of the painter Augustus John (1878-1961) earned the name Dorelia look. Meanwhile the Sapphic dance themes of Natalie Barney further extended the alternative lifestyle of an adventurous feminist culture [9] (Figure 2).
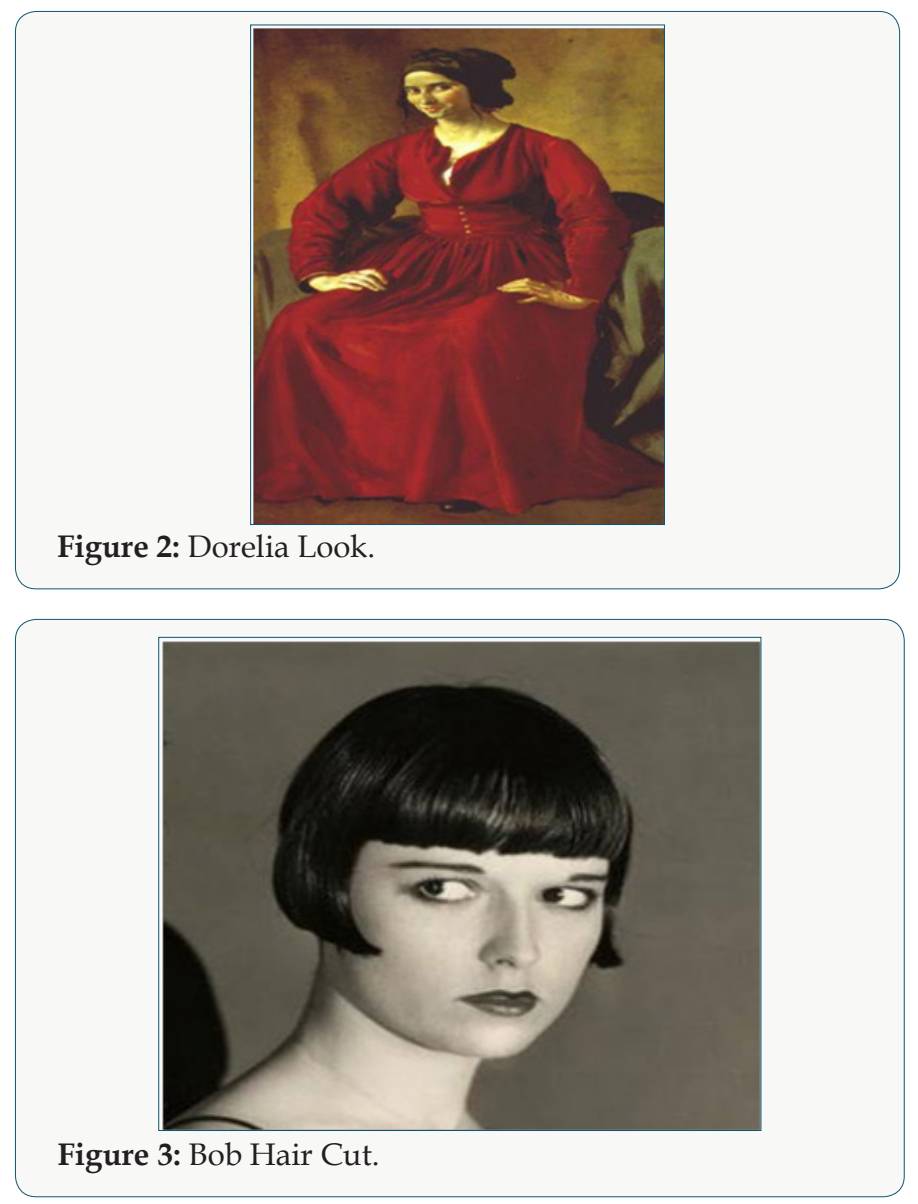

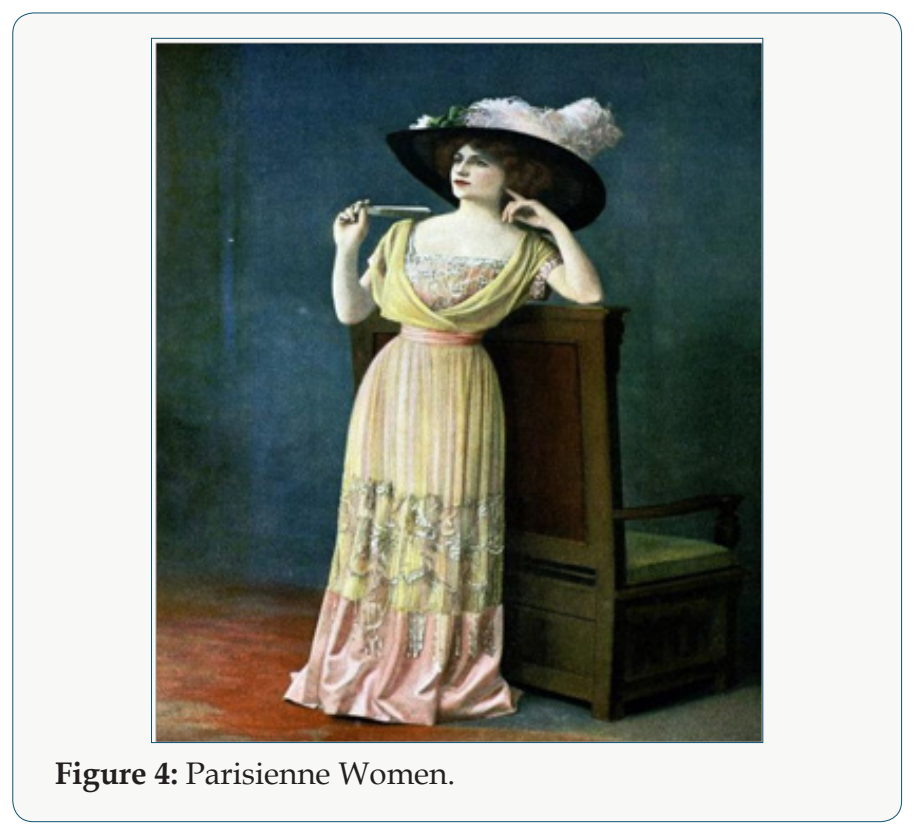

The 20th Century bob hairstyle which served as symbolic of independent and progressive woman furthered the cause of bohemian lifestyle. And Protagonist roles of Julia Roberts in "Pretty woman" and Uma Thurman in "Pulp fiction" did help to expand the reach of this new lifestyle [10] (Figure 3). To add on to this bohemian lifestyle is the works of Dora Carrington whose unique, colourful depiction of fruits, flowers, and a brightly plumed bird on a brass urn and the painting of Female Figure Lying on Her Back speaks about the intuitiveness and uninhibited feminine expressions [11]. Parisienne women preferred grotesquely large hats, gold or silver thread embellished patterns sometimes laced with flowers, fruits, feathers and ribbons" to add to the decorum. Even comic operas, "The bohemian Girl" did stage everyday dress design similar to bohemian look [12] (Figure 4).

\section{Bon chic Bon genre (BCBG)}

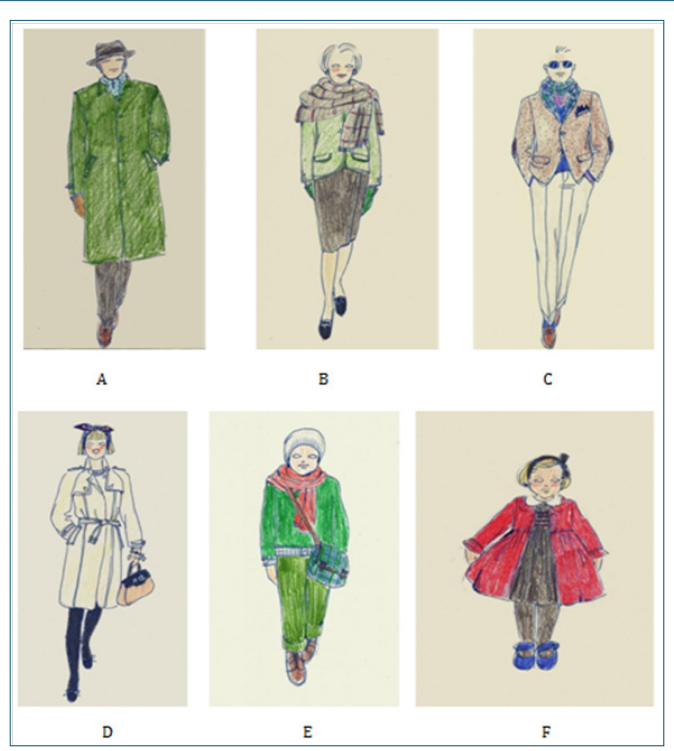

Figures 5: A: BCBG Grandfather; B: BCBG Grandmother; C: BCBG father Bon chic Bon genre; D: BCBG mother; E: BCBG son; F: BCBG daughter. 
Bon chic Bon genre refers to a subculture of stylish members of the Paris upper class who prefer being fashionable at the same time retaining the appearance of social respectability [7]. It literally means "good style", "good attitude". The list of BCBG includes: Hermès scarves; Montblanc pens; the colour loden green and the sartorial fabric list comprising of silk, cotton, linen, wool, tweed referring good taste to comfort [13]. What makes it the more adorable is the common belief that French beauty secrets are enshrined in BCBG concept that makes up the ubiquitous French style and it is evidently expressed as if looking through the Window "French eye of design" in the illustrations of Jeanne Aelia [14] (Figure 5).

Analogous to BCBG concept, Preppy style did exist in United States and in United Kingdom it is referred as Sloane rangers. Preppy otherwise known as Ivy league style reflects the popular essential style code of America and always an element or two is patronized by top US brands such as Ralf Lauren, Lilly Pulitzer and Tommy Hilfiger even today [15]. Unlike the decline of "Sloane rangers" of
UK in the recent times, the "preppy" style got rejuvenated by the Japanese van look of Kensuke Ishizu in early 21st century [11,15].

\section{Deconstructed Non-bourgeois bohemian}

Floral patterns, paisley or geome tric prints, mystic metal jewellery, head wrap or an oversized hat, feathery earrings, sandals or boots make a perfect prop for an unkempt environment [16]. Notwithstanding mixing up patterned and printed silhouettes, ruffles skirts with non symbolic accessories sports a crafty multi colored kitsch outlook [17]. This choice for non-bourgeois style undermines the free spiritedness and no prejudice barred approach in flaunting new semantic attributes a lag lamping attitude. The whole concept is about crossing the threshold limit and experimentation seeking inner harmony analogous to the bohemian rhapsody the 3rd best selling UK single of all time that focuses on a more emotional level [18]. This deconstructed trend entered the design houses of Diane von Furstenberg, Simone Rocha and Junya Watanabe in fall 2017 runway emphasizing the overall aesthetic carefree and feminine [19](Figure 6).

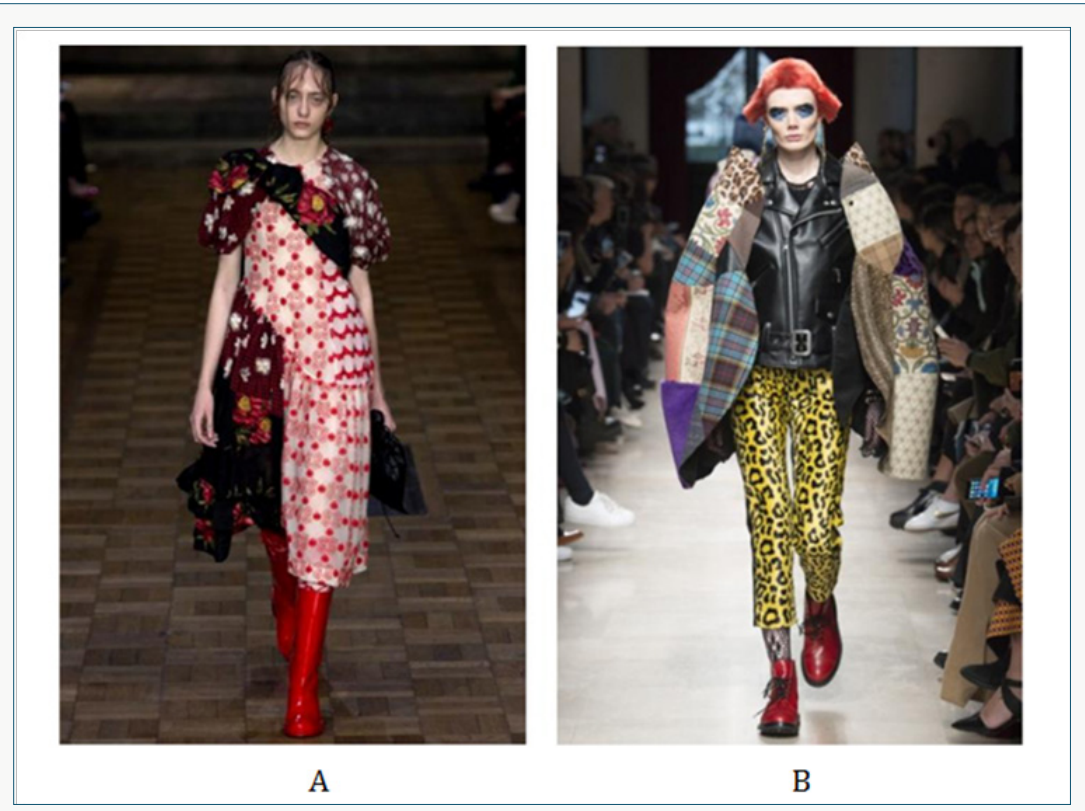

Figures 6: A: SS 2017- Simone Rocha; B: FW 2017- Junya watanabe.

\section{Conclusion}

For Gen Y Living in the moment, living their passion takes precedence over the preference to acquire the status symbols: Property, car, savings, etc [20]. Thus Non-indulgence in impersonating others provided the impetus to nurture value driven fashion solutions. And Fashion, particularly contemporary fashion, is all about appropriating the ostracized, the old, the déclassé, and making it new [21]. The reason to live in the moment deserves to make a style statement of their own instead of being conservative and complying by an aesthetic standard; "Norm core". Again are they completely oblivious to the Bourgeois theme, the answer is no.
Hence the choice would be to add on personal style flavour how ever non-descript it might be, thus pushing forward their style sense marked by their latent desires amidst retaining the adoration for French eye of design. In other words the Gen Y's expected choice is analogous to combination of Bourgeois and Bohemian.

\section{References}

1. Https://www.wgsn.com/design destination/city by city special reports/accessed 14 january 2018.

2. Harti, Umi N, Dadang M (2017) Modernity and lifestyle: Analysis of generation $\mathrm{Y}$ on creative industry product.The social sciences 12(1): 160166. 
3. Https://www.en.wikipedia.org/wiki/Bohemian style/accessed 10 January 2018.

4. Https://www.en.wikipedia.org/wiki/bon chic bon genre/accessed 12 January 2018.

5. Valerie steele (2005) Encyclopedia of clothing and fashion, Thomson gale, USA, 1 pp. 172.

6. Campbell, LA Pun, Addidas, Alexander Wang, (2017) Textile view magazine, Issue no 120, News and Womens wear lifestyle, SS19, pp. 246.

7. Https://www.telegraph.co.uk/newstopics/diana/11421941/sloane rangers/accessed 15 January 2018.

8. Https://www.en.wikipedia.org/wiki/Natalie Clifford barney/accessed 10 January 2018.

9. Https://www.visforvintage.net/2012/04/03/history of bob hairstyle/ accessed 11 January 2018.

10. Https://www.theartstory.org/artist Carrington Dora/accessed 12 January 2018.

11. Valerie steele (eds) (2005), Encyclopedia of clothing and fashion, Thomson gale, USA, 1: 340 .

12. Https://www.elle.com/fashiona12888/french bourgeois dressing louis vuitton/ accessed 13 January 2018.
13. Https://www.amidpriviledge.com/2010/12/french secrets bcbg bon chic bon genre/accessed 13 January 2018.

14. Https://www.usaloveit.com/preppy style/accessed 14 January 2018.

15. Https://www.fashionpirate.co.uk/collections/bana/accessed 15 January 2018.

16. Https://www.zaful.com/blog/boho definitely not boo hoo accessed 15 January 2018.

17. Https://www.andything.wordpress.com/2012/07/01/notes on notes and in depth analysis of bohemian rhapsody/ accesses 11 January 2018.

18. Https://www.realstylenetworks.com/fashion and style/2017/09/accessed 10 January 2018.

19. Rajiv S (2016) How Gen Y's spending patterns differ from previous generations. ET Bureau, The Economic Times, USA.

20. Https://www.susannaives.com/wordpress/2012/03/french fashion 1910/accessed 10 January 2018.

21. Https://www.nytimes.com/2009/06/17/fashion/18codes/accessed 14 January 2018.

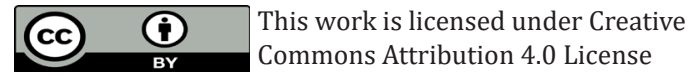

To Submit Your Article Click Here:

Submit Article

DOI: $10.32474 /$ LTTFD.2018.01.000116

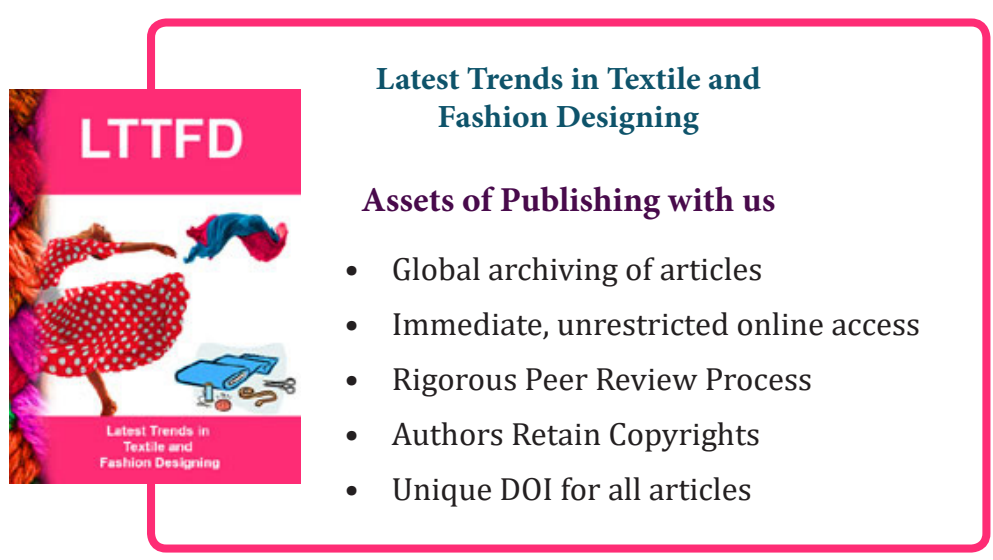

